\title{
Sustainable Production of Algal Biomass and Biofuels Using Swine Wastewater in North Carolina, US
}

\author{
Bo Zhang ${ }^{1}$, Lijun Wang ${ }^{1, *}$, Bilal A. Riddicka ${ }^{1}$, Rui Li ${ }^{1,2}$, Justin R. Able ${ }^{1}$, \\ Nana Abayie Boakye-Boaten ${ }^{1}$ and Abolghasem Shahbazi ${ }^{1}$ \\ 1 Department of Natural Resources and Environmental Design, North Carolina A \& T State University, \\ Greensboro, NC 27411, USA; bzhang@ncat.edu (B.Z.); bariddic@aggies.ncat.edu (B.A.R.); \\ ruilir1009@gmail.com (R.L.); jable@aggies.ncat.edu (J.R.A.); naboakye@aggies.ncat.edu (N.A.B.-B.); \\ ash@ncat.edu (A.S.) \\ 2 Joint School of Nanoscience and Nanoengineering, North Carolina A \& T State University, \\ Greensboro, NC 27411, USA \\ * Correspondence: lwang@ncat.edu; Tel.: +1-336-334-7787
}

Academic Editor: Andrew Kusiak

Received: 8 March 2016; Accepted: 11 May 2016; Published: 14 May 2016

\begin{abstract}
Algae were recently considered as a promising third-generation biofuel feedstock due to their superior productivity, high oil content, and environmentally friendly nature. However, the sustainable production became the major constraint facing commercial development of algal biofuels. For this study, firstly, a factorial experimental design was used to analyze the effects of the process parameters including temperatures of $8-25^{\circ} \mathrm{C}$, light intensity of $150-900 \mu \mathrm{mol} \cdot \mathrm{m}^{-2} \mathrm{~s}^{-1}$, and light duration of 6-24 h on the biomass yields of local alga Chlamydomonas debaryana in swine wastewater. The results were fitted with a quadratic equation $\left(R^{2}=0.9706\right)$. The factors of temperature, light duration, the interaction of light intensity-light duration, and the quadratic effect of temperature were statistically significant. When evaluating different scenarios for the sustainable production of algal biomass and biofuels in North Carolina, US, it showed that: (a) Growing C. debaryana in a 10-acre pond on swine wastewater under local weather conditions would yield algal biomass of 113 tonnes/year; (b) If all swine wastewater generated in North Carolina was treated with algae, it will require 137-485 acres of ponds, yielding biomass of 5048-10,468 tonnes/year and algal oil of 1010-2094 tonnes/year. Annually, hundreds of tonnes of nitrogen and phosphorus could be removed from swine wastewater. The required area is mainly dependent on the growth rate of algal species.
\end{abstract}

Keywords: sustainable production of algal biomass; algal biofuels; swine wastewater; Chlamydomonas debaryana; year-round production

\section{Introduction}

With growing concerns about declining fossil fuel supplies, environmental issues, and increasing demand of fossil fuels, renewable biofuels have received a large amount of research attention [1]. While first- and second-generation biofuels (i.e., biodiesel, corn-based ethanol, and advanced biofuels) are already in the market or entering into the market [2], algae were recently considered as a promising third-generation biofuel feedstock due to their superior productivity, high oil content, and environmentally friendly nature [3,4]. The algal technology for biofuels production has greatly been advanced in the past decade $[5,6]$. It is recognized that the sustainable production of algal biomass is indeed the major drawback to commercializing algae-based biofuels [7].

Recently, an increase in swine production has resulted in greater amounts of swine wastes and treatment problems [8]. For example, because flush collection is the common swine manure management practice in North Carolina (NC) [9], in which dilute manure is stored in outdoor 
uncovered lagoons, this manure management may lead to environmental and health issues, such as ammonia emission, odor, and infectious diseases [10]. Agricultural wastewater without a proper treatment possesses surplus nitrogen, phosphorus, and other chemicals. If discharged, it may lead to the eutrophication of receiving water, surface water pollution, and leaching to ground water [11]. On the other hand, algal growth requires three major nutrients of carbon, nitrogen, and phosphorus, while other nutrients may be required in trace amounts, including calcium, chlorine, chromium, cobalt, copper, iron, magnesium, manganese, potassium, silica, sodium, sulfur, and zinc [12,13]. When growing algae in outdoor ponds or large-scale photobioreactors, the use of commercial fertilizers would substantially increase production costs of algae-derived biofuels. For aforementioned reasons, wastewater is often considered as a proper growth medium for algae, increasing the environmental sustainability [13] and the economic sustainability of algal biofuels [14].

The purpose of this research is to address a critical barrier in the sustainability of algal biofuels by studying the algal growth in the swine wastewater under local weather conditions and analyzing possible means of improvement. For this study, a local alga of Chlamydomonas debaryana was grown in swine wastewater under various environmental conditions; the biomass production was optimized by using the central composite design; and obtained information was applied to analyzing the potential of algal biomass production in North Carolina.

\section{Materials and Methods}

\subsection{Microalgal Strain and Cultivation Conditions}

Chlamydomonas debaryana AT24 was isolated from the local swine wastewater lagoon [15]. Our previous study showed that this species has a higher lipid content than Chlorella vulgaris and keeps growing at a moderate growth rate under relatively low temperatures $[15,16]$. For this study, C. debaryana was cultured with swine wastewater, which was collected from an uncovered lagoon at the university swine farm. The swine wastewater was filtrated with a Whatman quantitative filter paper ( $8 \mu \mathrm{m}$ pore) to remove large, non-soluble, particulate solids. After filtration the wastewater was autoclaved for $15 \mathrm{~min}$ at $121{ }^{\circ} \mathrm{C}$. The compositions of swine wastewater and medium used in this study are summarized in Table 1. Proteose medium is used to compare different growth behaviors of this alga.

Table 1. Properties of swine wastewater and proteose medium.

\begin{tabular}{ccc}
\hline Nutrients & Autoclaved Swine Wastewater & Proteose \\
\hline COD (mg/L) & 2300 & 1286 \\
Ammonia (ppm) & 50.2 & 6.3 \\
Total inorganic nitrogen (ppm) & - & 90 \\
Total phosphorous (ppm) & 130 & 204 \\
pH & 9.3 & 7 \\
\hline
\end{tabular}

-: negligible.

An AlgaeTron Multi-Cultivator MC 1000 photobioreactor (Photon Systems Instruments, Drasov, Czech Republic), which consists of eight $100-\mathrm{mL}$ tubular reactors, was used to mimic environmental variations. A detailed description was provided elsewhere [16]. Typically, $72 \mathrm{~mL}$ of autoclaved swine wastewater and $8 \mathrm{~mL}$ of microalgal inoculum were loaded into a $100 \mathrm{~mL}$ tube, and gases were supplied to each tube at a flow rate of $100 \mathrm{~mL} / \mathrm{min}$ to provide $\mathrm{CO}_{2}$ source and increase mixing. To obtain a gas mixture containing $\mathrm{CO}_{2}$, the original $\mathrm{CO}_{2}$ source with a $99.9 \%$ purity was mixed with air through mass flow meters (Alicat Scientific, Tucson, AZ, USA). The ratios of $\mathrm{CO}_{2}$ and air after mixing were $5 \%$ and 95\% (volume), respectively. Microalgae were cultured in the swine wastewater for 15-30 days with varying temperature $\left(8-25^{\circ} \mathrm{C}\right)$, light intensities $\left(50-900 \mu \mathrm{mol} \cdot \mathrm{m}^{-2} \mathrm{~s}^{-1}\right)$, and light durations $(2-24 \mathrm{~h})$. All experiments and analyses were performed in triplicate or duplicate. 


\subsection{Determination of Microalgae Growth and Nutrient Analysis}

For sampling, 30-50 $\mathrm{mL}$ of microalgal broth was collected from the photobioreactor, and centrifuged at $2600 \times g$ and $20^{\circ} \mathrm{C}$ for $15 \mathrm{~min}$. Supernatants were separated to determine the nutrient removal from wastewater. Supernatants were filtered using a $0.45-\mathrm{mm}$ nylon membrane filter. Then, the filtrates were appropriately diluted and analyzed for the chemical oxygen demand (COD), ammonia, and total phosphorus according to the Lamotte Smart 3 colorimeter manual [17]. To determine microalgae growth, the collected microalgal cells were dried at $105^{\circ} \mathrm{C}$ until the sample reached equilibrium moisture content.

\subsection{Central Composite Experimental Design and Evaluation}

The central composite design (CCD) is a factorial experimental design with center points, augmented with a group of axial points that are used to estimate curvature [18]. Three factors of cultivation temperature, light intensity, and light duration were optimized through CCD, which includes 20 sets of experiments including include eight factorial points (cubic points), six axial points (star points), and six replicates at the center point. The relative and interactive effects of three factors on the biomass yield after 15-day growth were investigated at three levels. The obtained experimental data were fitted to the second-degree polynomial equation:

$$
Y=B_{0}+\sum_{i=1}^{n} B_{i} X_{i}+\sum_{i<j}^{n} B_{i j} X_{i} X_{j}+\sum_{j=1}^{n} B_{j j} X_{j}^{2}
$$

where $Y$ is the biomass yield in 15 days; $X_{1}$ is the cultivation temperature; $X_{2}$ is the light intensity; $X_{3}$ is the light period per day (i.e., light duration); $B_{0}$ is a constant; and $B_{i}, B_{j j}$, and $B_{i j}$ are linear, quadratic, and interaction coefficients, respectively. The variable $X_{i}$ in Equation (1) is the non-coded independent variables.

Three-dimension (3D) response surfaces were performed to elucidate the individual and mutual effects of the experimental variables on the response [19].

The statistical significance of each item in Equation (1) was assessed with analysis of variance (ANOVA) by fitting the experimental data to a second-order polynomial equation. The statistical significance level cut-off was chosen as $p=0.05$.

\subsection{Estimations of Algal Biomass Production}

The microalgae were assumed to be grown in the open raceway pond. To minimize the difference between the laboratory photobioreactor and open raceway ponds, the rates of $\mathrm{NH}_{3}$ volatilization and water evaporation were assumed to be same in both systems, which were approximately $50 \%$ and $10 \%$ of total volume after a 15-day culture, respectively.

The light intensity in C. debaryana culture was estimated by using Equation (2) [20]:

$$
I=I_{0} e^{-\left(k_{c} C_{D}+k_{l}\right) d}
$$

where $I_{0}$ is the light intensity on the water surface $\left(\mu \mathrm{mol} \cdot \mathrm{m}^{-2} \mathrm{~s}^{-1}\right), k_{c}$ is the coefficient for cell density, $C_{D}$ is the cell density $(\mathrm{g} / \mathrm{L}), k_{l}$ is the coefficient for algal medium, and $\mathrm{d}$ is the water depth $(\mathrm{cm})$. In order determine the values of $k_{c}$ and $k_{l}, C$. debaryana cultures were mixed well and placed under sunlight. The light intensity values on the water surface $\left(I_{0}\right)$ were measured by using a LI-1400 DataLogger with LI-190R Quantum sensor (LI-COR Biosciences, Lincoln, NE, USA), and the light intensity values in the water $(I)$ were measured by using a LI-1400 DataLogger with LI-192 Underwater Quantum sensor (LI-COR Biosciences, Lincoln, NE, USA). Combining data of cell concentrations $\left(C_{D}\right)$ and the water depth $(d)$, the values of $k_{c}$ and $k_{l}$ were experimentally determined as 0.03725 and 0.3525 , respectively.

The light intensity on the Earth's surface depends on many factors, such as radiation angles and weather conditions. Thus, only the average values of light intensities were used in the estimation. 
According to our periodic monitoring, the light intensities on the water surface $\left(I_{0}\right)$ were assumed to be $900,1400,900$, and $600 \mu \mathrm{mol} \cdot \mathrm{m}^{-2} \mathrm{~s}^{-1}$ during spring, summer, fall, and winter, respectively.

A raceway pond is often shallow enough so that the water temperature is fairly even from top to bottom and changes with air temperature. To establish the estimation in this study, the average temperature of each month was used. The temperature data was adopted from [21], while the data of average daytime was obtained from [22].

According to USDA, North Carolina (NC) holds the second largest hog inventory with 8.4 million head in 2014 [23]. Each hog was assumed to produce 1.2 tonnes/year of waste with a total solid content of $10 \%$ [24]. Since flush collection is the common swine manure management practice in NC [9], 1.2 tonnes/year/head water was assumed to be used to flush hog wastes and dilute the solid content to $5 \%$, resulting in a use of 10.1 million $\mathrm{m}^{3}$ /year water. When comparing the needed area for treating swine wastewater, the raceway pond with a water depth of $20 \mathrm{~cm}$ was assumed to be used to grow algae year-round. These data are summarized in Table S1 (S: Supplemental materials).

While evaluating the biofuel production from $C$. debaryana, biological properties of $C$. debaryana (such as lipid content and protein content) grown in open raceway ponds were assumed to be the same as those of alga grown in the laboratory photobioreactor.

\section{Results and Discussion}

\subsection{Effects of Environmental Parameters}

\subsubsection{Light Saturation}

The growth of microalgae was known to remarkably depend on the appropriate light intensity, light duration, and light wavelength [25]. Our initial study on C. debaryana AT24 indicated that it is not sensitive to photoinhibition, and there was a possible "saturation" effect [15]. For this paper, a sufficiently broad range of light intensity $\left(50-900 \mu \mathrm{mol} \cdot \mathrm{m}^{-2} \mathrm{~s}^{-1}\right)$ was selected to show conditions of "insufficient" and "saturation" light intensities. Figure 1 shows the biomass yields obtained at $20^{\circ} \mathrm{C}$ under continuous lighting. When the light intensity increased from 50 to $150 \mu \mathrm{mol} \cdot \mathrm{m}^{-2} \mathrm{~s}^{-1}$, the biomass yields in 15 and 30 days increased by $53 \%$ and $45 \%$, respectively. However, a substantially higher level of intensity showed no observable influence. The results confirmed the apparent light saturation effect on the growth of this microalga. Compared with Chlorella vulgaris, which has shown a strong photoinhibition effect, the light saturation effect of $C$. debaryana indicates that the cultivation process may require less attention of the photoinhibition problem.

\subsubsection{Effect of Light Duration}

The effect of the light duration on biomass yields of $C$. debaryana AT 24 was studied (Table 2), while it was cultivated at $20^{\circ} \mathrm{C}$ and light intensity of $150 \mu \mathrm{mol} \cdot \mathrm{m}^{-2} \mathrm{~s}^{-1}$. When compared with the continuous illumination, the biomass yields for the 15-day cultures decreased by $20.9 \%, 49.2 \%$, and $69.4 \%$ for $12 \mathrm{~h}, 6 \mathrm{~h}$, and $2 \mathrm{~h}$ illumination, respectively. Reduced light exposure time resulted in apparently insufficient photosynthesis and biomass accumulation. 


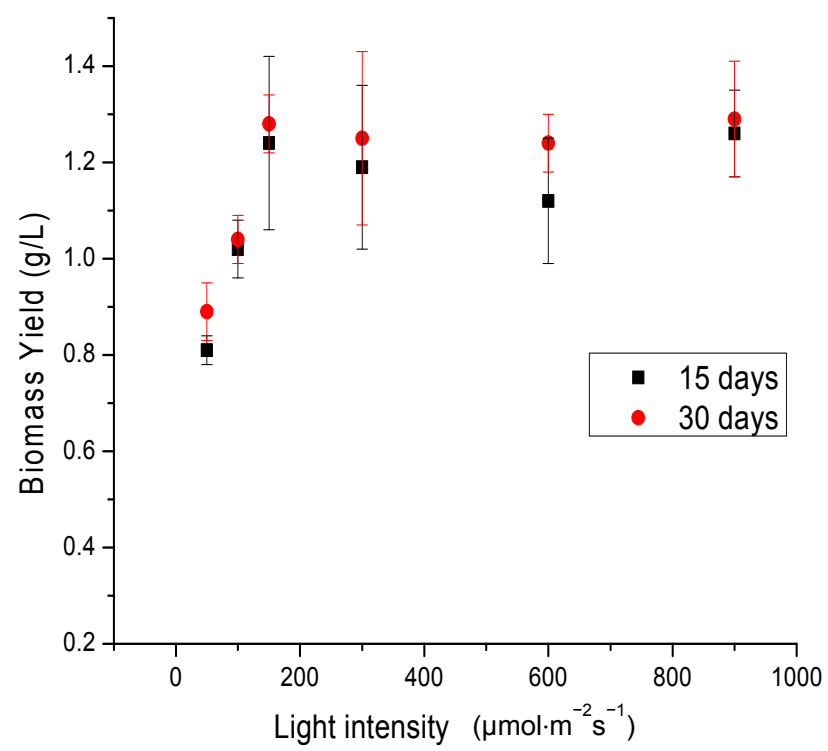

Figure 1. Biomass yields of $C$. debaryana AT24 cultivated at $20^{\circ} \mathrm{C}$ under continuous lighting. Error bars represent the standard deviation.

Table 2. The effect of light/dark (L/D) cycle on the biomass yield of C. debaryana AT24 at $20^{\circ} \mathrm{C}$.

\begin{tabular}{ccc}
\hline L/D Cycle (h:h) & Biomass Yield in 15 Days (g/L) & Biomass Yield in 30 Days (g/L) \\
\hline $24: 0$ & $1.24 \pm 0.18^{*}$ & $1.28 \pm 0.06$ \\
$12: 12$ & $0.98 \pm 0.09$ & $1.25 \pm 0.04$ \\
$6: 18$ & $0.63 \pm 0.07$ & $0.82 \pm 0.10$ \\
$2: 22$ & $0.38 \pm 0.12$ & $0.54 \pm 0.02$ \\
\hline
\end{tabular}

* Error bars represent the standard deviation.

\subsubsection{Effect of $\mathrm{CO}_{2}$ and Dilution on Biomass Yields}

A mixture of $5 \mathrm{vol} \% \mathrm{CO}_{2}$ and $95 \mathrm{vol} \%$ air was used to bubble the photobioreactor at the rate of $100 \mathrm{ml} / \mathrm{min}$. Biomass yields of C. debaryana obtained at $25^{\circ} \mathrm{C}$ under continuous lighting are shown in Table 3. When this microalga was cultured in the swine wastewater, the biomass yields after 15 and 30 days were approximately 2.4 and $2.9 \mathrm{~g} / \mathrm{L}$, respectively. Compared with cultures using air bubbling (biomass yields of $0.72-0.77 \mathrm{~g} / \mathrm{L}$ ), the biomass yields were almost triplicated by the excess $\mathrm{CO}_{2}$ supplement.

Table 3. Biomass yields of $C$. debaryana in media supplied with a mixture of $5 \mathrm{vol} \% \mathrm{CO}_{2}$ and $95 \mathrm{vol} \%$ air under continuous lighting.

\begin{tabular}{|c|c|c|c|c|c|}
\hline Media & $\begin{array}{l}\text { Wastewater (Air } \\
\text { Bubblingonly) }\end{array}$ & Wastewater & Wastewater & $\begin{array}{c}\text { Diluted } \\
\text { Wastewater * }\end{array}$ & $\begin{array}{l}\text { Proteose } \\
\text { Medium }\end{array}$ \\
\hline $\begin{array}{l}\text { Light intensity } \\
\left(\mu \mathrm{mol} \cdot \mathrm{m}^{-2} \mathrm{~s}^{-1}\right)\end{array}$ & 150 & 150 & 300 & 150 & 150 \\
\hline $\begin{array}{l}\text { Biomass yield in } \\
15 \text { days }(\mathrm{g} / \mathrm{L})\end{array}$ & $0.72 \pm 0.11$ & $2.41 \pm 0.21$ & $2.42 \pm 0.15$ & $1.44 \pm 0.18$ & $1.56 \pm 0.23$ \\
\hline $\begin{array}{l}\text { Biomass yield in } \\
30 \text { days }(\mathrm{g} / \mathrm{L})\end{array}$ & $0.77 \pm 0.13$ & $2.87 \pm 0.17$ & $2.91 \pm 0.12$ & $1.53 \pm 0.08$ & $1.66 \pm 0.12$ \\
\hline
\end{tabular}

The composition of the swine wastewater is highly variable and dependent on many factors, such as environmental conditions and operation parameters. According to the literature [26], the concentrations of COD, ammonia, and total Kjeldahl nitrogen in swine wastewater are within the range of 1517-8184 mg/L, 885-1985 mg/L, and 958-2124 mg/L, respectively. The high-strength swine 
wastewater might require dilution before adopting algae in it [15]. As shown in Table 3, the results of diluted and non-diluted wastewater showed that there is no significant inhibition effect when using original swine wastewater. Compared with the compositions reported in the literature, the swine wastewater collected from the uncovered lagoon has a lower COD value of 2050-2600 mg/L [27] and a lower ammonia content $(<180 \mathrm{mg} / \mathrm{L})$ [28], representing a low-strength wastewater that might be used directly as the algal medium. In addition, algal biomass yield in diluted wastewater is similar to that of proteose medium, which might be limited by the nutrients available.

\subsubsection{Removal of Nutrients from Swine Wastewater}

The COD value of wastewater is a measure of the amount of chemicals that consume dissolved oxygen [29]. Swine wastewater contains a considerable amount of nutrients, such as nitrogen and phosphorus (as shown in Table 1). Most of these nutrients contribute to the COD value. Microalgal growth reduced most nutritional contents of the wastewater. The data of nutrients removal under cultivation conditions used in this study is summarized in Table S2. The average removal ratio of COD, ammonia, and phosphorous after 15 -day culture were $59 \%, 81.4 \%$, and $17.4 \%$, respectively.

\subsection{Regression Analysis and ANOVA Test}

The regression analysis was applied to study the relationships between the response (biomass productivity of 15-day culture) and three effect factors (temperature, light intensity, and light duration) (Table 4). Our previous publications showed that the exponential growth phase of $C$. debaryana often ended before day $15[15,30]$. Meanwhile, compared with conventional wastewater treatment processes that typically take 5-20 days [31], treating wastewater with algae culture for 15 days is relatively reasonable. After regression analysis of the experimental data, a second-order polynomial equation was obtained, and the predictive model developed is listed as Equation (3):

$$
\begin{array}{cc}
Y(\text { unit: } \quad g / L)=10^{-3} \times\left(-1967.8089+219.0324 X_{1}+0.8165 X_{2}+64.6227 X_{3}-0.0085 X_{1} X_{2}\right. \\
\left.-2.3220 X_{1} X_{3}-0.0006 X_{2} X_{3}-4.9092 X_{1}^{2}-0.0005 X_{2}^{2}+0.1277 X_{3}^{2}\right)
\end{array}
$$

with a $\mathrm{R}^{2}$ of 0.9706 , implying that this response model could explain $97.1 \%$ of the variability within the investigated range. The highest algal biomass yield $(Y)$ was found to be $1.21 \mathrm{~g} / \mathrm{L}$ with this equation, when the temperature $X_{1}$, light intensity $X_{2}$, and light duration $X_{3}$ were $18.4^{\circ} \mathrm{C}, 651 \mu \mathrm{mol} \cdot \mathrm{m}^{-2} \mathrm{~s}^{-1}$, and $24 \mathrm{~h} /$ day, respectively. Since the longest day time in the Piedmont Triad area (NC) is $14.5 \mathrm{~h} /$ day, the highest algal biomass yield of $0.96 \mathrm{~g} / \mathrm{L}$ was reached when the temperature and light intensity were $18.3{ }^{\circ} \mathrm{C}$ and $652 \mu \mathrm{mol} \cdot \mathrm{m}^{-2} \mathrm{~s}^{-1}$, respectively. According to the local climatic conditions and Equation (3), calculated biomass yields of $C$. debaryana are summarized in Table 5.

Table 4. Experimental results of the experimental design.

\begin{tabular}{ccccc}
\hline Design Number & Temperature $\left({ }^{\circ} \mathbf{C}\right)$ & $\begin{array}{c}\text { Light Intensity } \\
\left(\mu \mathbf{m o l} \cdot \mathbf{~ m}^{-\mathbf{2}} \mathbf{s}^{-\mathbf{1}} \mathbf{)}\right.\end{array}$ & $\begin{array}{c}\text { Light Duration } \\
(\mathbf{h} / \text { day) }\end{array}$ & $\begin{array}{c}\text { Biomass Yield in } \\
\text { 15 Days (g/L) }\end{array}$ \\
\hline 1 & 15 & 150 & 12 & 0.71 \\
2 & 25 & 150 & 12 & 0.65 \\
3 & 15 & 600 & 12 & 0.73 \\
4 & 25 & 600 & 12 & 0.69 \\
5 & 15 & 150 & 6 & 0.50 \\
6 & 25 & 150 & 6 & 0.52 \\
7 & 15 & 600 & 6 & 0.62 \\
8 & 25 & 600 & 6 & 0.66 \\
9 & 20 & 300 & 8 & 0.83 \\
10 & 20 & 300 & 8 & 0.79 \\
11 & 8 & 600 & 12 & 0.15 \\
12 & 20 & 300 & 8 & 0.75 \\
\hline
\end{tabular}


Table 4. Cont.

\begin{tabular}{ccccc}
\hline Design Number & Temperature $\left({ }^{\circ} \mathbf{C}\right)$ & $\begin{array}{c}\text { Light Intensity } \\
\left(\mu \mathbf{m o l} \cdot \mathbf{~ m}^{-\mathbf{2}} \mathbf{s}^{-\mathbf{1}} \mathbf{)}\right.\end{array}$ & $\begin{array}{c}\text { Light Duration } \\
(\mathbf{h} / \mathbf{d a y})\end{array}$ & $\begin{array}{c}\text { Biomass Yield in } \\
\mathbf{1 5} \text { Days }(\mathbf{g} / \mathbf{L})\end{array}$ \\
\hline 13 & 20 & 300 & 8 & 0.78 \\
14 & 10 & 600 & 12 & 0.17 \\
15 & 15 & 150 & 24 & 1.11 \\
16 & 15 & 900 & 24 & 1.16 \\
17 & 8 & 150 & 12 & 0.09 \\
18 & 10 & 150 & 12 & 0.15 \\
19 & 25 & 150 & 24 & 0.72 \\
20 & 25 & 900 & 24 & 0.77 \\
\hline
\end{tabular}

Table 5. Estimation of the growth rate and biomass yields of C. debaryana under local weather conditions.

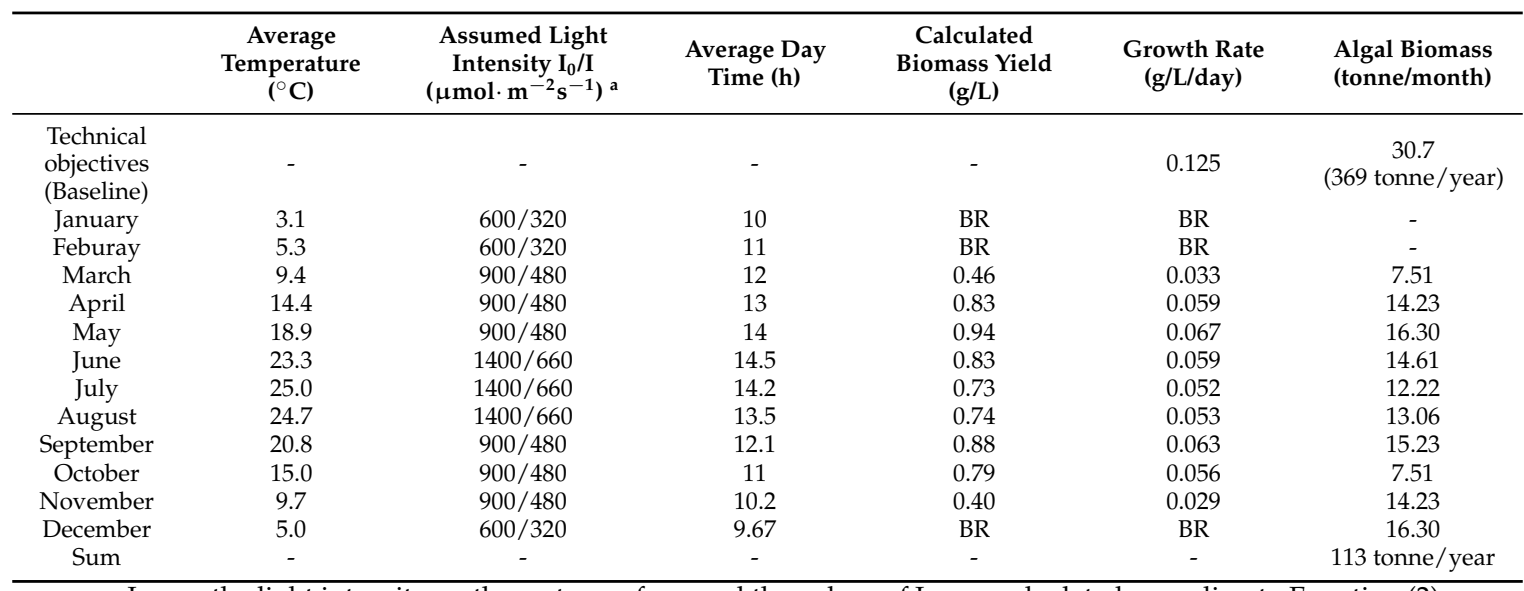

a: $\mathrm{I}_{0}$ was the light intensity on the water surface, and the values of I were calculated according to Equation (2) at the water depth of $5 \mathrm{~cm}$ and algal cell concentration of $0.25 \mathrm{~g} / \mathrm{L}$. BR: beyond the range of Equation (3); -: Not available.

ANOVA was applied to generate $p$ values. The $p$-values for the cultivation temperature $\left(X_{1}\right)$, light intensity $\left(X_{2}\right)$, light duration $\left(X_{3}\right), X_{1} X_{2}, X_{1} X_{3}, X_{2} X_{3}, X_{1}^{2}, X_{2}^{2}$, and $X_{3}^{2}$ were $1.3942 \times 10^{-7}, 0.10$, $0.0107,0.40,0.0005,0.9664,7.4556 \times 10^{-7}, 0.467$, and 0.83 , respectively. If a statistical significance level cut-off is chosen as $p=0.05$, it is concluded that the factors of the cultivation temperature $\left(X_{1}\right)$, light duration $\left(X_{3}\right)$, the interaction between cultivation temperature and light duration $\left(X_{1} X_{3}\right)$, and the quadratic effect of temperature $\left(X_{1}^{2}\right)$ were statistically significant.

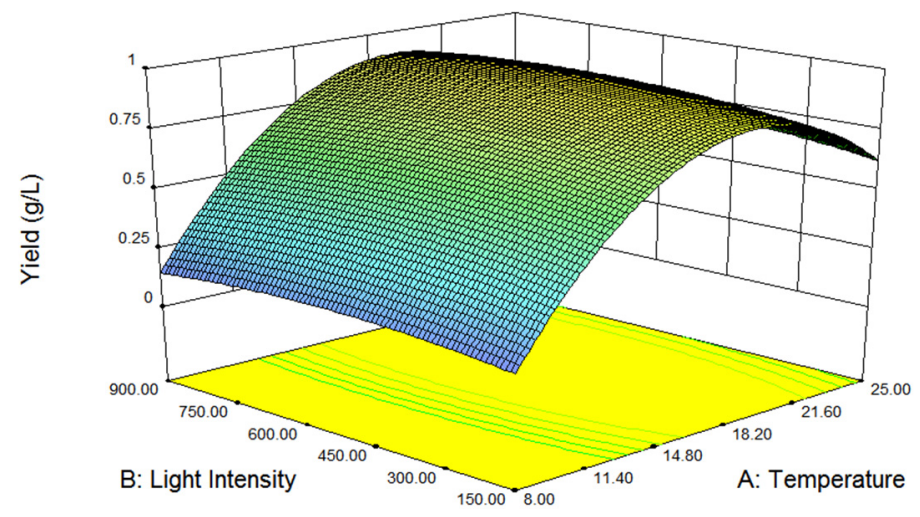

(a)

Figure 2. Cont. 


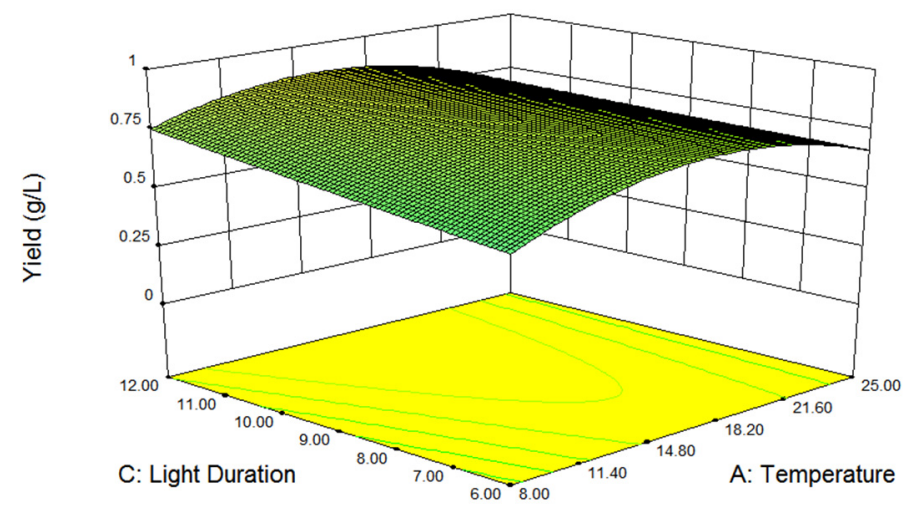

(b)

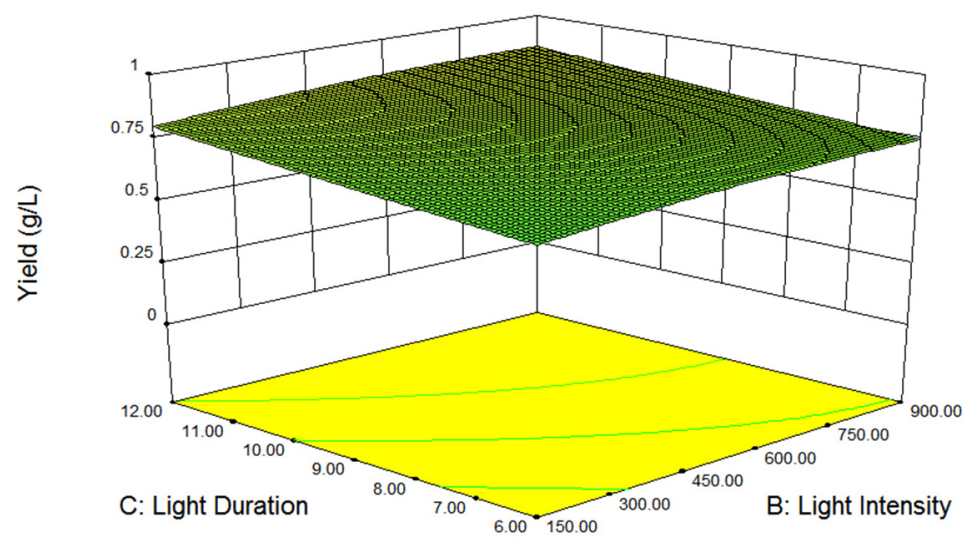

(c)

Figure 2. Biomass yield in $3 \mathrm{D}$ response surfaces. (a) effects of temperature and light intensity $\left(X_{3}=14.5 \mathrm{~h} /\right.$ day); (b) effects of temperature and light duration $\left(X_{2}=651 \mu \mathrm{mol} \cdot \mathrm{m}^{-2} \mathrm{~s}^{-1}\right)$; and (c) effects of light duration and light intensity $\left(X_{1}=18.4^{\circ} \mathrm{C}\right)$.

Three-dimension (3D) response surfaces were performed to elucidate mutual effects of the experimental variables on the response (Figure 2). The results confirmed that the interaction of temperature-light duration was significant. A higher light intensity may be able to make up the inadequate light duration. The optimal growth temperature is around $19{ }^{\circ} \mathrm{C}$.

\subsection{Estimation of Annual Biomass Yield of C. Debaryana}

Following scenario was used to estimate the annual biomass yield of $C$. debaryana under local weather conditions: Algae were grown in a race-way pond of 10 acres with $20 \mathrm{~cm}$ water depth, and harvested at a rate of $5 \mathrm{~cm}$ (i.e., $2000 \mathrm{~m}^{3}$ ) per day. Algae were not grown during December, January, and February.

When comparing different scenarios, the baseline was the technical objectives that were reported by US National Laboratories [32]. These technical objectives are (1) the algal productivity is assumed to reach $25 \mathrm{~g} / \mathrm{m}^{2} /$ day; (2) cell concentration is $0.5 \mathrm{~g} / \mathrm{L}$ (i.e., algal growth rate is $0.125 \mathrm{~g} / \mathrm{L} /$ day); (3) lipid content of algae is $25 \%$; and (4) $\mathrm{N}$ and $\mathrm{P}$ demands are $8.7 \%$ and $1.3 \%$ of dry algae, respectively.

The calculation results are summarized in Table 5. According to the technical objectives that were proposed by US government agencies, a race-way pond of 10 acres could produce algal biomass at a yield of 30.7 tonnes/month or 369 tonnes/year. If $C$. debaryana was grown under NC weather conditions, the growth rate would be between 0.029 and $0.067 \mathrm{~g} / \mathrm{L} /$ day, resulting an annual biomass yield of 113 tonnes/year. The annual biomass yield obtained using C. debaryana is at least three times less than the objectives proposed by agencies. 
In order to improve the sustainable production of algal biomass in North Carolina, this study provided following information:

(1) As a native species, C. debaryana could stand local cold weather, and remain fast-growing around $15^{\circ} \mathrm{C}$. If a covered photobioreactor system with temperature controll was applied, the year-round production of algal biomass could be realized and improved.

(2) A nearby $\mathrm{CO}_{2}$ source will be a perk for the biomass production, because a $5 \mathrm{vol} \%$ supply increased the biomass yields of $C$. debaryana by three times.

\subsection{Evaluation of the Potential of Biomass and Biofuel Production}

Scenarios are summarized in Table 6 . Scenario 1 is the baseline scenario that used the technical objectives proposed by US government agencies. As described in the Materials and Method section, annual swine wastewater production in NC was assumed to be 10.1 million $\mathrm{m}^{3} /$ year, and algae were grown continuously in the raceway ponds at a growth rate of $0.125 \mathrm{~g} / \mathrm{L} /$ day to treat this amount of wastewater. The harvest mode of algae was to collect the top $5 \mathrm{~cm}$ of algal broth every day. Treating 10.1 million $\mathrm{m}^{3}$ of wastewater required 137 acres, and annual algal biomass production could reach 5048 tonnes/year, yielding algal oil of 1010 tonnes/year. Nitrogen and phosphorus removals from swine wastewater would be 439 and 65.5 tonnes/year, respectively.

Table 6. Evaluation of the potential of biomass and biofuel production from C. debaryana.

\begin{tabular}{|c|c|c|c|c|}
\hline Scenario & Baseline & This Study & $\begin{array}{c}\text { Lower Growth Rate } \\
\text { with New } \\
\text { Culture/Harvest Mode }\end{array}$ & $\begin{array}{c}\text { Lower Growth Rate } \\
\text { with Limited Area }\end{array}$ \\
\hline Algal growth rate & $0.125 \mathrm{~g} / \mathrm{L} /$ day & $\begin{array}{l}0.07 \mathrm{~g} / \mathrm{L} / \text { day }(\text { i.e., } 1 \mathrm{~g} / \mathrm{L} \\
\text { per two weeks) }\end{array}$ & $0.07 \mathrm{~g} / \mathrm{L} /$ day & $0.07 \mathrm{~g} / \mathrm{L} /$ day \\
\hline Harvest mode & $0.05 \mathrm{~m}$ depth/day & $\begin{array}{l}\text { A complete harvest } \\
\text { every } 2 \text { weeks }\end{array}$ & $0.05 \mathrm{~m}$ depth/day & $0.05 \mathrm{~m}$ depth/day \\
\hline $\begin{array}{l}\text { Algal biomass } \\
\text { (tonnes/year) }\end{array}$ & 5048 & 10,095 & 10,468 & 2957 \\
\hline Algal oil (tonnes/year) & 1010 (25\% of biomass) & 2020 (20\% of biomass) & 2094 (20\% of biomass) & 565 (20\% of biomass) \\
\hline $\begin{array}{c}\text { Removed N } \\
\text { (tonnes/year) }\end{array}$ & 439 & $554-908$ & $574-941$ & $162-266$ \\
\hline
\end{tabular}

Scenario 2 is based on the experimental information that was obtained from this study and [15]. Algal culture was operated at the batch mode, and the biomass yield normally could reach $1 \mathrm{~g} / \mathrm{L}$ within two weeks, giving a growth rate of $0.07 \mathrm{~g} / \mathrm{L} /$ day. Algae were harvested every two weeks. In order to treat 10.1 million $\mathrm{m}^{3}$ wastewater, this scenario required 485 acres of ponds, which is 3.54 times more than that of Scenario 1. Since the lipid content of $C$. debaryana is $\sim 20 \%$ (wt) of total dry biomass, the algal oil production would be 2020 tonnes/year. Annually, 554-908 tonnes of nitrogen and 484-898 tonnes of phosphorus could be removed from swine wastewater.

Scenario 3 assumed that the area of ponds was 485 acres, but algae were harvested daily and new wastewater was added at the same rate. With these assumptions, biomass yield was slightly higher than that of Scenario 2. The results indicated that the fed-batch mode of operation might be better than the batch mode.

Scenario 4 adopted the fed-batch mode of operation, but the area of ponds were set to be equal to the baseline scenario (i.e., 137 acres). Since the growth rate $C$. debaryana is slower than the assumed value in Scenario 1, both biomass and oil production were lower than those of Scenario 1. However, phosphorus removal is higher than the baseline scenario, the possible reasons are different species or assumptions used. 
Scenario 5 was developed from the Scenario 3. Because $C$. debaryana only shows a moderate growth rate among algal strains isolated from the swine wastewater lagoon [15], it is assumed that swine wastewater was treated by growing algal species A and B that have a $50 \%$ higher and lower growth rate than C. debaryana (i.e., $0.105 \mathrm{~g} / \mathrm{L} /$ day and $0.035 \mathrm{~g} / \mathrm{L} /$ day), respectively. If the same area of 485 acres was used for wastewater treatment, these two algae will yield biomass of 15,702 and 5234 tonnes/year, respectively. These numbers gave an idea how the algal growth rate might affect the annual algal biomass productivity.

\section{Conclusions}

Sustainable production is one of the critical barriers in the algal research. In order to solve this problem, Chlamydomonas debaryana AT24 was grown in swine wastewater under various environmental conditions, and the results were further used to analyze the potential of algal biomass/biofuels production in North Carolina, USA. For this paper, it was found that (1) there was an apparent light saturation effect on the growth of this microalga; (2) the optimal growth temperature was $\sim 19^{\circ} \mathrm{C}$; and (3) the biomass yields were almost triplicated by the excess $\mathrm{CO}_{2}$ supplement. The biomass production was further optimized using the factorial experimental design, and the results were fitted with a regression quadratic model $\left(R^{2}=0.9706\right)$. The highest algal biomass yield $(Y)$ was found to be $1.21 \mathrm{~g} / \mathrm{L}$ with this model, when the temperature, light intensity, and light duration were $18.4^{\circ} \mathrm{C}, 651 \mu \mathrm{mol} \cdot \mathrm{m}^{-2} \mathrm{~s}^{-1}$, and $24 \mathrm{~h} /$ day, respectively. The factors of cultivation temperature, light duration, the interaction of light intensity-light duration, and the quadratic effect of temperature were statistically significant.

Growing $C$. debaryana in a 10-acre pond on swine wastewater under NC weather conditions was estimated to yield algal biomass of 113 tonnes/year, which is three times lower than the objective set by US government agencies. Based on information obtained through this study, both better designed photobioreactor system and a nearby $\mathrm{CO}_{2}$ source could help improve algal biomass production in North Carolina.

Further evaluating the potential of algal biomass and biofuels production showed that, if all swine wastewater generated in NC was treated with this alga, it will require 137-485 acres of ponds, yielding biomass of 5048-10,468 tonnes/year and algal oil of 1010-2094 tonnes/year. The required area is mainly dependent on the growth rate of the algal species.

Supplementary Materials: The following are available online at www.mdpi.com/2071-1050/8/5/477/s1, Table S1: Inventory data for estimation of algal biomass production from swine wastewater, Table S2: Nutrients removal by C. debaryana AT24 after 15-30 days culture.

Acknowledgments: This publication was made possible by Grant Number NC.X2013-38821-21141 and NC.X-294-5-15-130-1 from the U.S. Department of Agriculture (USDA-NIFA). Its contents are solely the responsibility of the authors and do not necessarily represent the official views of the National Institute of Food and Agriculture.

Author Contributions: For research articles with several authors, a short paragraph specifying their individual contributions must be provided. The following statements should be used "Bo Zhang and Lijun Wang conceived and designed the experiments; Bo Zhang, Bilal A. Riddick, Rui Li, Nana Abayie Boakye-Boaten, and Justin R. Able performed the experiments; Bo Zhang and Lijun Wang analyzed the data; Abolghasem Shahbazi contributed reagents/materials/analysis tools; Bo Zhang and Lijun Wang wrote the paper.

Conflicts of Interest: The authors declare no conflict of interest. The founding sponsors had no role in the design of the study; in the collection, analyses, or interpretation of data; in the writing of the manuscript, and in the decision to publish the results.

\section{References}

1. Santacesaria, E. What future for the renewable energy. Trends Renew. Energy 2015, 1, 57-58. [CrossRef]

2. Xian, M. Recent development of bioenergy and biorefinery in china. Trends Renew. Energy 2015, 1, 129-130. [CrossRef]

3. Chisti, Y. Biodiesel from microalgae. Biotechnol. Adv. 2007, 25, 294-306. [CrossRef] [PubMed] 
4. Hasan, R.; Zhang, B.; Wang, L. Microalgae for biodiesel production and waste water treatment. In Biomass Processing, Conversion and Biorefinery; Zhang, B., Wang, Y., Eds.; Nova Science Publishers, Inc.: Hauppauge, New York, NY, USA, 2013; pp. 277-288.

5. Sutherland, D.L.; Howard-Williams, C.; Turnbull, M.H.; Broady, P.A.; Craggs, R.J. Enhancing microalgal photosynthesis and productivity in wastewater treatment high rate algal ponds for biofuel production. Bioresour. Technol. 2015, 184, 222-229. [CrossRef] [PubMed]

6. Picardo, M.; de Medeiros, J.; Monteiro, J.; Chaloub, R.; Giordano, M.; de Queiroz Fernandes Araújo, O. A methodology for screening of microalgae as a decision making tool for energy and green chemical process applications. Clean Technol. Environ. Policy 2013, 15, 275-291. [CrossRef]

7. Department of Energy Office of Energy Efficiency and Renewable Energy. Algal Biofuels Strategy. In Proceedings of the Algal Biofuels Strategy Workshop, Charleston, SC, USA, 26-27 March 2014.

8. Cheng, D.; Wang, L.; Shahbazi, A.; Xiu, S.; Zhang, B. Catalytic cracking of crude bio-oil from glycerol-assisted liquefaction of swine manure. Energy Convers. Manag. 2014, 87, 378-384. [CrossRef]

9. US EPA. Agstar-Anaerobic Digestion on Swine Operations. Available online: http://www.epa.gov/ outreach/agstar/anaerobic/swine.html (accessed on 15 July 2015).

10. Aillery, M.; Gollehon, N.; Johansson, R.; Kaplan, J.; Key, N.; Ribaudo, M. Managing Manure to Improve air and Water Quality; US Department of Agriculture, Economic Research Service: Washington, DC, USA, 2005.

11. Correll, D.L. Role of phosphorus in the eutrophication of receiving waters: A review. Environ. Qual. 1998, 27, 261-266. [CrossRef]

12. Christenson, L. Algal Biofilm Production and Harvesting System for Wastewater Treatment with Biofuels By-Products. Master's Thesis, Utah State University, Logan, UT, USA, 2011.

13. Christenson, L.; Sims, R. Production and harvesting of microalgae for wastewater treatment, biofuels, and bioproducts. Biotechnol. Adv. 2011, 29, 686-702. [CrossRef] [PubMed]

14. Chen, P.; Min, M.; Chen, Y.; Wang, L.; Li, Y.; Chen, Q.; Wang, C.; Wan, Y.; Wang, X.; Cheng, Y.; et al. Review of the biological and engineering aspects of algae to fuels approach. Int. J. Agric. Biol. Eng. 2009, 2, 1-30.

15. Zhang, B.; Wang, L.; Hasan, R.; Shahbazi, A. Characterization of a native algae species chlamydomonas debaryana: Strain selection, bioremediation ability, and lipid characterization. BioResouces 2014, 9, 6130-6140. [CrossRef]

16. Hasan, R.; Zhang, B.; Wang, L.; Shahbazi, A. Bioremediation of swine wastewater and biodiesel production by using chlorella vulgaris, chlamydomonas reinhardtii, and chlamydomonas debaryana. J. Pet. Environ. Biotechnol. 2014, 5, 175. [CrossRef]

17. LaMotte. Lamotte Smart 3 Colorimeter Operator's Manual. Available online: http://www.geotechenv.com/ Manuals/LaMotte_Manuals/smart3_colorimeter_operators_manual.pdf (accessed on 12 May 2016).

18. Techapun, C.; Charoenrat, T.; Watanabe, M.; Sasaki, K.; Poosaran, N. Optimization of thermostable and alkaline-tolerant cellulase-free xylanase production from agricultural waste by thermotolerant streptomyces sp. Ab106, using the central composite experimental design. Biochem. Eng. J. 2002, 12, 99-105. [CrossRef]

19. Xie, T.; Sun, Y.; Du, K.; Liang, B.; Cheng, R.; Zhang, Y. Optimization of heterotrophic cultivation of chlorella sp. For oil production. Bioresour. Technol. 2012, 118, 235-242. [CrossRef] [PubMed]

20. Wu, X.; Merchuk, J.C. Simulation of algae growth in a bench scale internal loop airlift reactor. Chem. Eng. Sci. 2004, 59, 2899-2912. [CrossRef]

21. WeatherSpark. Average Weather for Greensboro, North Carolina, USA. Available online: https:// weatherspark.com/averages/30409/Greensboro-North-Carolina-United-States (accessed on 12 May 2016).

22. Wikipedia. Climate of North Carolina. Available online: http://en.wikipedia.org/wiki/Climate_of_North_ Carolina (accessed on 12 May 2016).

23. USDA. U.S. Hogs and Pigs Inventory Down 2 Percent. Available online: http://www.nass.usda.gov/ Newsroom/2014/09_26_2014.php (accessed on 12 May 2016).

24. Deutsche Gesellschaft für Sonnenenergie; ECOFYS (Firm). Planning and Installing Bioenergy Systems: A Guide for Installers, Architects, and Engineers; Routledge: New York, NY, USA, 2004.

25. Carvalho, A.; Silva, S.; Baptista, J.; Malcata, F.X. Light requirements in microalgal photobioreactors: An overview of biophotonic aspects. Appl. Microbiol. Biotechnol. 2011, 89, 1275-1288. [CrossRef] [PubMed]

26. Shin, J.-H.; Lee, S.-M.; Jung, J.-Y.; Chung, Y.-C.; Noh, S.-H. Enhanced cod and nitrogen removals for the treatment of swine wastewater by combining submerged membrane bioreactor (mbr) and anaerobic upflow bed filter (aubf) reactor. Process Biochem. 2005, 40, 3769-3776. [CrossRef] 
27. Rahman, Q.M.; Wang, L.; Zhang, B.; Xiu, S.; Shahbazi, A. Green biorefinery of fresh cattail for microalgal culture and ethanol production. Bioresour. Technol. 2015, 185, 436-440. [CrossRef] [PubMed]

28. Poach, M.; Hunt, P.; Sadler, E.; Matheny, T.; Johnson, M.; Stone, K.; Humenik, F.; Rice, J. Ammonia volatilization from constructed wetlands that treat swine wastewater. Trans. ASAE 2002, 45, 619. [CrossRef]

29. University of Wisconsin. Chemical Oxygen Demand. Available online: http://www.chem.wisc.edu/ courses/116/OtherDoc/Labs/COD_Lab.pdf (accessed on 19 April 2016).

30. Li, R.; Zhang, B.; Xiu, S.; Wang, H.; Boaten, N.A.B.; Holmes, B.M.; Wang, L.; Shahbazi, A. Characteristics of pine gasification ash and its effects on chlamydomonas debaryana growth. BioResources 2016, 11, 1919-1929. [CrossRef]

31. Grady, C.L., Jr.; Daigger, G.T.; Love, N.G.; Filipe, C.D. Biological Wastewater Treatment; CRC Press: Boca Raton, FL, USA, 2011.

32. Davis, R.; Fishman, D.; Frank, E.; Wigmosta, M.; Aden, A.; Coleman, A.; Pienkos, P.; Skaggs, R.; Venteris, E.; Wang, M. Renewable Diesel from Algal Lipids: An Integrated Baseline for Cost, Emissions, and Resource Potential from a Harmonized Model; Argonne National Laboratory: Argonne, IL, USA, 2012.

(C) 2016 by the authors; licensee MDPI, Basel, Switzerland. This article is an open access article distributed under the terms and conditions of the Creative Commons Attribution (CC-BY) license (http://creativecommons.org/licenses/by/4.0/). 